\title{
Simulation Realization of Sliding Mode Control for Second Order System with M Language
}

\author{
Yuqiang $\mathrm{Jin}^{1}$, Jianhong $\mathrm{Shi}^{2}$,Junwei Lei ${ }^{2}$ a and Zijian Lin $^{2}$ \\ ${ }^{1}$ Department of Ordnance Science and Technology, Naval aeronautical and astronautical University, \\ Yantai, China \\ ${ }^{2}$ Department of control engineering, Naval aeronautical and astronautical University, Yanti, 264001 \\ aleijunwei@126.com
}

Keywords: Sliding mode, Stability, Robustness, Matlab, Program

\begin{abstract}
Aiming at a class of two order systems with single input and non minimum phase, a sliding mode control method is used to design the controller. And the problem of using Matlab software $\mathrm{M}$ language programming is studied. Finally, the simulation results show that the design of the controller and the programming is reasonable.
\end{abstract}

\section{Introduction}

In 1950s, the Soviet Union scholars put forward the sliding mode variable structure control, which originated from the relay control. The main difference between it and the conventional control method is that the control of the discontinuity. This control method has experienced 50 years of development, and gradually formed a relatively independent branch, becoming a common design method of automatic control system. The difference between this control method and other control methods lies in that the structure of the system is not fixed. It uses a special kind of control mode, forcing the state of the system to slide down to the desired point along the trajectory of the sliding surface. Sliding mode control has good control performance for nonlinear system, and can be applied to multi input and multi output system. When the system is in the sliding model, the model error and parameter changes of controlled object as well as external interference are not very sensitive. What's more, the physical realization is relatively simple and easy so as to provide a better solution for the control of complex industrial. The main obstacle of this method in the practical application is that when the state trajectories reach the sliding surface which is determined by the mode, it is difficult to move strictly along the reserved sliding mode to the equilibrium point, but slide back and forth across the both sides closer to it, resulting in buffeting.

\section{Model Description}

The research object of this paper, that is the controlled object, is selected as the following two order system model:

$$
\begin{array}{r}
\dot{x}_{1}=5 x_{1}+4 x_{2} \\
\dot{x}_{2}=7 x_{2}-9 x_{1}+u
\end{array}
$$

By designing the control law u to realize the control goal of the state tracking, that is to achieve $x_{1} \rightarrow x_{1}^{d}$,in which $x_{1}^{d}$ is the expected value.

\section{Controller Design}

Define error variables as:

$$
e=x_{1}-x_{1}^{d}
$$

The sliding mode surface is selected as the:

$$
s=\dot{e}+10 e
$$

The theoretical deduction is as follows: 
If $s=0$, then

$$
\dot{e}=-10 e
$$

Known as

$$
v=\frac{1}{2} s^{2}
$$

Then

$$
\dot{v} \leq 0
$$

there must be $v \rightarrow 0, s \rightarrow 0$.

Taking the derivative of $\mathrm{v}$,obtained:

$$
\dot{v}=s \dot{S}
$$

Taking the derivative of $e=x_{1}-1$, obtained:

$$
\dot{e}=\dot{x}_{1}=5 x_{1}+4 x_{2}
$$

By the synovial surface $s=\dot{e}+10 e$,obtained:

in which,

$$
\dot{s}=\ddot{e}+10 \dot{e}
$$

We make the control

$$
\begin{gathered}
\ddot{e}=\dot{x}_{1}=5\left(5 x_{1}+4 x_{2}\right)+4\left(7 x_{2}-9 x_{1}+u\right) \\
\dot{s}=5\left(5 x_{1}+4 x_{2}\right)+4\left(7 x_{2}-9 x_{1}\right)+4 u+10\left(5 x_{1}+4 x_{2}\right)
\end{gathered}
$$

So,

$$
u=\frac{1}{4}[-\delta-5 s]
$$

$$
\delta=5\left(5 x_{1}+4 x_{2}\right)+4\left(7 x_{2}-9 x_{1}\right)+10\left(5 x_{1}+4 x_{2}\right)
$$

\section{Simulation Program}

We design the time interval is $0.001 \mathrm{~s}$, the simulation time is $10 \mathrm{~s}$, the initial value is 0 and the expected value is 1 . Then we make $x \rightarrow x^{d}$ through the program design and design the control quantity $u$ to control the rudder deflection $\delta$. The simulation program is as follows:

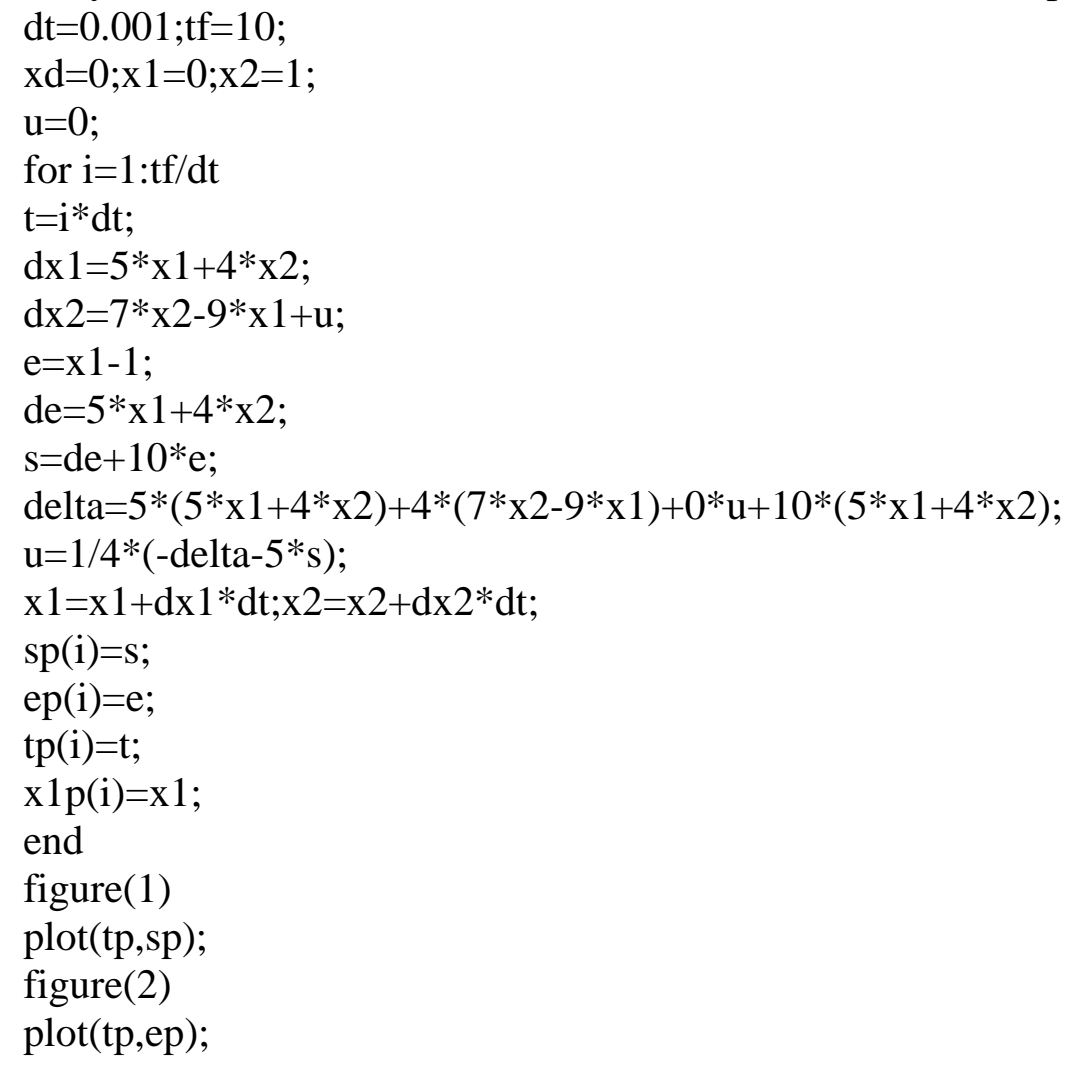


figure(3)

plot(tp,x1p);

\section{Simulation Result and Analysis}

The simulation results which are obtained from the basic principle analysis realized by the above controller design and simulation program are as follows:

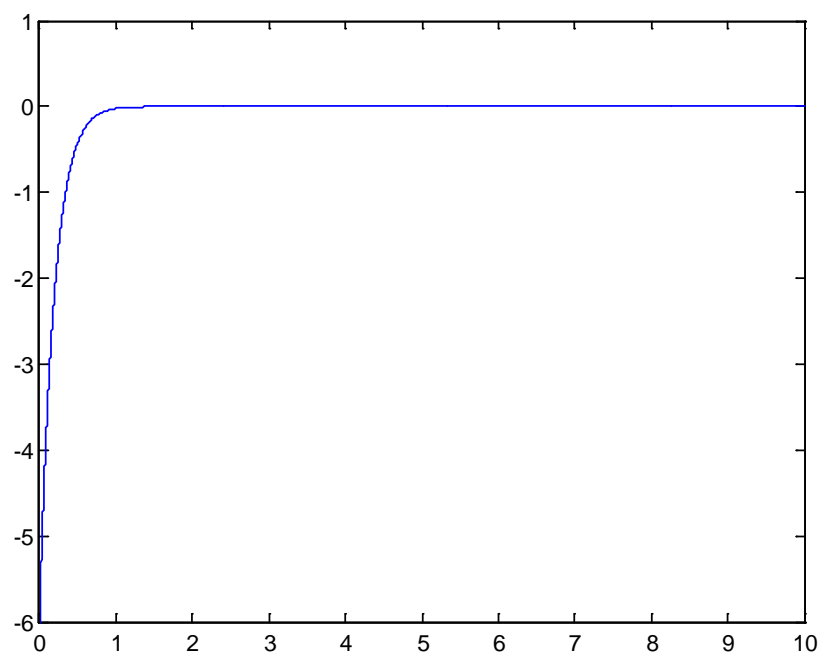

Fig. 1 PID control simulation

From the figure above, we can see that the design of sliding mode controller can make the reaching condition satisfied, thereby reaching the sliding surface in finite time. And in the process of reaching rapid, the system has small buffeting. Simulation through the MATLAB shows that adding the sliding mode in the control system can have a certain effect in reducing the oscillation for the rapid stability of the system.

\section{Conclusions}

In this paper, we study the design of the sliding mode controller for A class of two order linear systems with single input and non minimum phase. In particular, the chattering problem of sliding mode control is reduced by using the proportional terms instead of the traditional shear. Finally, the Matlab software $\mathrm{M}$ language is used to study the problem of its program implementation, and the corresponding analysis is carried out from the simulation results.

\section{References}

[1]Bolender M.A, and Doman ,D.B.A Nonlinear Model for the Longitudinal Dynamics of a Hypersonic Airbreathing Vehicle. In: AIAA Guidance,Navigation,and Control Conference,San Francisco,CA,Aug.2005,AIAA 2005-6255

[2]Williances.T, Bolender, M.A, Doman, D.B. An Aerothermal Flexible Mode Analysis of a Hyper Sonic Vehicle. In: AIAA Annospheric Flight Mechanics Conference and Exhibit, AIAA 2006-6647

[3]Shaughnessy J.D, Pinckney S.Z, Hypersonic Vehicle Simulation Model: Winged-cone Configuration, NASA,TM-102610

[4]Shahliar Kesllmiri, Richard Colgren, Six-DOF Modeling and Simulation of a Generic Hypersonic Vehicle for Control and Navigation Purposes, AIAA 2006-6694.

[5]Clark A D, Mirmirani M D, Wu C,et a1. An aero-propulsion integrated elastic model of a generic airbreathing hypersonic vehicle, In: AIA A Guidance, Navigation, and Control Conference and Exhibit, Keystone, US-AIA A 2006,6560:1-20.

[6]Huo Y. A1titllde and Velocity Tracking Contro1 for an Air-breathing Hypersonic Cruise 
Vehicle[C]. AIAA Guidance Navigation and Control Conference and Exhibit,2006,calorado,AlAA 2006-6695:1-10.

[7]J.T. Parker, A. Serrani, S. Yurkovich, M. A. Bolender, D. B. Doman. Control-oriented Modeling of an Air-breathing Hypersonic Vehicle. Journal of Guidance, Control, and Dynamics, V01.30, no.3, pp.856-869,2007

[8]Bolender M A Doman D B.Nonlinear longitudinal dynamical model of an air-breathing hypersonic vehicle. Journal of Spacecraft R and Rockets,2007,44 (2) :374-387.

[9] M.A. Bolender, D.B. Doman. Nonlinear Longitudinal Dynamical Model of an Air-Breathing Hypersonic Vehicle. Journal of Spacecraft and Rockets,2007,44(2):374-387.

[10]Kuipers M, Ioannou P and Y. Huo. Adaptive Control of an Aeroelastic Airbreathing Hypersonic Cruise Vehicle. In: AIA A Guidance, Navigation, and Control Conference and Exhibit, Honolulu, USA, AIAA 2007-6326

[11]Kuipers M, Ioannou P, Fidan B, et a1.Robust adaptive multiple model controller design for an airbreathing hypersonic vehicle model, In: AIA A Guidance, Navigation, and Control Conference and Exhibit, Honolulu, USA, AIAA 2008-7142. 